\title{
Improving population and poverty estimates with citizen surveys: evidence from East Africa
}

\section{ABSTRACT (296 words)}

The paper sets out to explore the possibility that citizen-led surveys provide a better coverage of populations and specifically of hard-to-reach poorer areas than the international standardised household surveys which are the basis for many of the estimates used in assessing progress towards meeting the MDGs and will be for the SDGs. This hypothesis is based on the argument that, the local volunteer enumerators of citizen-led surveys are likely to be more sensitive to the specificities of local population distribution and (recent) changes than those centrally trained; and may be more effective at reaching hard-to reach groups such as those nomadic groups and those in urban slums.

To test the hypothesis, the results of UWEZO (meaning 'capability') surveys have been compared at a regional level with those of contemporaneous DHS surveys in Kenya, Tanzania and Uganda for estimates of access to water and electricity. Overall, at national level, we find that UWEZO estimates for access to clean water were lower at a statistically significant level than those of DHS and these differences were statistically significant at the $0.01 \%$ level; in particular, the DHS values were much higher in regions where there are high concentrations of nomads and of urban slums, implying that the UWEZO surveys 'catch' more poverty.

The suggestion therefore is that citizen surveys such as UWEZO provide better, and more accurate, coverage of the poorest of the poor. Using the lowest estimate of the percentage 'missing' in urban slums and extrapolating to all developing countries, there are an estimated 369 million missing from the sampling frames of standardised household surveys worldwide. This has important implications for the 'Leave no one behind' appeal of the UN Secretary General and for the UN's 'Data Revolution'. Some suggestions are made about how to progress improved population estimates. 


\section{Keywords}

East Africa; Citizen-led Surveys; Hard-to-reach Populations, Poverty Estimates

\section{Highlights}

Household surveys omit by design wholly, and in practice partially, several groups

These omitted groups constitute a substantial proportion of the poorest of the poor

Citizen volunteer surveys include some deprivation indicators comparable with DHS

Contemporaneous DHS estimates are statistically lower in areas with large urban slums

These citizen surveys are clearly better at 'catching'/‘finding' those in poverty 


\section{IMPROVING POPULATION AND POVERTY ESTIMATES WITH CITIZEN SURVEYS:}

\section{EVIDENCE FROM EAST AFRICA}

\section{I: INTRODUCTION AND BACKGROUND}

The purpose of this paper is to document the probable undercount in census estimates of the world's population, the certain undercount of poverty in both censuses and household surveys, and to demonstrate the extent of the undercount in the standardised household surveys in East Africa. This introductory section sets the stage by briefly describing population statistics and poverty estimation; the (growing?) concerns with undercounts of population and poverty; the specific problems with household surveys and why they are 'worse' than censuses; and finally the characteristics of citizen-led surveys.

\subsection{Population Statistics and Poverty Estimates}

For several decades and in some countries for centuries, populations have been counted through national, usually decennial, traditional censuses in which enumerators go to households with a questionnaire on a specific date or in a very short period and, if no one is at home, will return once or twice (UN, 2016a). Inter-censal population estimates have usually depended on reliable systems for registering births and deaths and monitoring migration (ONS, 2016; Statistics Canada, 2015)). There is a tendency in the richer countries to move towards registration data (Valente, 2010) or on combining data from, for example, an updated housing registry, with other sources such as the land registry and the central bank ${ }^{1}$ (Statistics Netherlands, 2011); but these obviously depend on high quality registration systems, and the most appropriate methodologies are still being discussed (UN, 2016b). In most middle and low income countries, however, vital registration systems do not really exist and have never been fully functioning (Chan et al., 2010; Powell, 1981; Vlahov et al., 2011; Alkire and Samman, 2014), and there has been a similar decline in donor interest in censuses and vital registration systems (Setel et al., 2007), as evidenced by the demise of the International Institute for Vital Registration and Statistics. More than 100 countries do not have functioning systems to register births or deaths (World Bank/WHO, 2014), with fewer than one in five births 
occur in countries with complete civil registration systems, although there has been some progress recently in Latin America and Africa (World Bank/ WHO, 2014).

For poverty (and other deprivation) estimates, some countries run national economic and social surveys (Pakistan Bureau of Statistics, 2011; Sri Lanka, 2009); but the main sources are increasingly the internationally standardized surveys with reasonably large sample sizes (the Demographic and Health Surveys (DHS), the Living Standard Measurement Surveys (LSMS), and the Multiple Indicator Cluster Surveys (MICS). There is the obvious "throwing the baby out with the bath-water" problem with this move away from censuses to relying on surveys because drawing a sample for a survey depends on having a sampling frame in the first place which is frequently based on the census ${ }^{2}$. Clearly any problem with the census, if used as the sampling frame for a national survey, will lead to that sampling frame being biased. In addition, household surveys almost always have less complete coverage by design than censuses in ways discussed later in this section. But there has-rather strangely ${ }^{3}$ - been little recognition of the problems in using household surveys to count or measure absolute numbers and the rates of income poverty or other forms of deprivation (e.g. hunger, employment, access to water and sanitation), until recently (Author, 2013; Villegas and Samman, 2015); and this is especially true for children who are the focus of many development goals such as the Millenium Development Goals (MDGs) and the Sustainable Development Goals (SDGs).

The issue is covered by Atkinson and Marlier (2010) but only very briefly, which is surprising given the focus of their book is on social inclusion. Mishra, Barrere, Hong \& Khan (2008) claim to correct for bias in HIV sero-prevalence estimates from national household surveys including not only non-response in 14 countries but also non-household population groups in five countries. But their estimates of the non-household populations, which appear to be based solely on census reports, are very low and not consistent with the evidence.

Nevertheless, the problem of census undercounts has been a concern of census officials and researchers for several decades. In developed countries, the major effort has of course been on 
ensuring as complete coverage of the census as possible in the first place. But, in addition, the issue of population undercount in the United States because of illegal immigration from Latin America (mostly Mexico) has preoccupied several researchers (Passel and Cohn, 2010; PEW Research Center, ongoing since 2004); and the UK's Office of National Statistics have been pre-occupied with including non-household groups for over a decade (Joloza, 2009).

There have been similar concerns in developing countries. Some commentators/ researchers have pointed out the general problem of undercounts in developing countries (Buettner and Garland, 2008; ODI, 2015); or have focussed on particular groups in developing countries as a whole such as victims of HIV/AIDS (Kalipeni et al., 2004; Richter and Desmond, 2007; Zimba and Tembo, 2008), the homeless (CARDO, 2003; Peressini, Mcdonald, \& Hulchanski, 2010), pastoralists (Misra and Malhotra, 1982), prisoners (Walmsley, 2008), refugees (Kohn, 2011; Refugees International, 2007); and slum dwellers ; (Davis, 2006; Montgomery, 2009). In addition, there have been several country-specific studies of population undercounts of specific groups in developing countries: for example of Bangladeshi immigrants in India (Pempel, 2011), Afghan immigrants in Iran (Abbasi-Shavazi and Sadeghi, 2011) and of the Chinese poor in Malaysia (Riggg,1991); of the problems encountered when using police as enumerators in China (Di, 2011) and Indonesia (Dwinosumono, 2006); of street children and slum dwellers in Egypt (Sabry, 2010), India (Agarawal, 2011; Chandrasekar, 2005; Patel, 1990), Indonesia (McCarthy, 2003) and Philippines (Berner, 1997); scheduled castes/ tribes in India (Committee on Protection of Tribal Areas, 2011; Gill,2007); and of internal migrants in Vietnam (Pincus and Sender, 2008).

The approach here is rather different: based on a comprehensive and systematic approach to the problem of population undercounts, we search in each country for the most likely missing groups and estimate the extent to which they are undercounted.

\subsection{Using household surveys - rather than censuses - to assess poverty}


The problem with using household surveys to assess the absolute level of poverty or of any related characteristic is that, in contrast to the view of Munoz and Scott (2004), they are an inappropriate instrument for obtaining information about the poorest of the poor, especially in developing countries (see Petterson, 2005). This is because household surveys, with rare exceptions, typically omit by design:

1. those not in households because they are homeless (although there are debates about the definitions - see Peressini, Mcdonald, \& Hulchanski, 2010, p. 1, chap. 8.3). ;

2. those who are in institutions, including refugee camps (UNHCR, 2015); and

3. mobile, nomadic or pastoralist populations (Petterson, 2005; Thornton et al., 2003).

In addition, in practice, because they are difficult to reach, household surveys will typically underrepresent:

4. those in fragile, disjointed, or multiple occupancy households (because of the difficulty of identifying them) (Szreter et al., 2004)

5. those in urban slums (because of the difficulty of identifying and interviewing) (Davis, 2006; UN Habitat, 2011);

6. may omit certain areas of a country deemed to pose a security risk (Author, 2005 and 2011);

7. older women in Sahelian countries (Randall and Coast, 2016)

8. servants (slaves) in rich households (Anti-Slavery, 2015)

If one wanted an ostensive — as distinct from a theoretical — definition of the "poorest of the poor", the above collection of eight population sub-groups could hardly be bettered. Evidence for these 8 categories has been laid out more extensively in a previous article in this journal (Author, 2013), where the bottom-up counting method suggested that there were perhaps as many as 400 million of 
the poorest of the poor missing from the sampling frames; in addition, for many of the categories, there is some evidence for the IN-DEPTH network (Sankoh and Bypass, 2012).

But, as Author (2013) showed, none of the four main standardized household surveys - the DHS, the LFS, the LSMS, and the MICS - had anything to say about the coverage of the homeless, institutional populations, the mobile and/or any special arrangements to cover slum areas.

Population censuses are, of course, themselves surveys of a kind, and, as we have illustrated above, have faced many of the same problems in the past; but a modern, politically independent Census will intend to include the mobile (because they refer to those present in the household on a specific day or night), will cover those in institutions, will attempt to cover those in urban slums and in less secure areas exhaustively, will (if necessary) carry out special counts of the homeless, and will attempt to estimate the numbers of pastoralists, with varying degrees of success (Misra and Malhotra, 1982). In other words, a Census can potentially solve many of the problems of omitted populations; but this is not possible for household surveys.

Author (2013) provides illustrations of how censuses may themselves not always provide a complete sampling frame through problems of coverage of those who may be excluded for political or practical reasons, and problems of enumerating specific groups such as servants in households, mobile populations, the homeless, and those in institutions; and with all those problems being compounded by variations in the level of reporting of coverage. Moreover, census officials in developing countries, even if they are making considerable efforts to ensure complete coverage (Randall 2015), often encounter severe difficulties in implementation (as referred to above in Indonesia); so that some have either left out some groups by design or have been forced to omit certain areas or groups, which may well have included many of the poorest.

\subsection{Citizen Led Surveys}


These were started in India by a large NGO (Pratham) to provide alternative analyses of the low levels of learning among children whether in or out of school. They depend on a large army of citizen volunteers who are given basic training to administer a simple questionnaire. The model has spread to Mali, Mexico, Nigeria, Pakistan and Senegal and into the three East African countries under the title UWEZO (meaning capability in Swahili). The Results for Development (R4D) Institute carried out a well-funded evaluation of citizen led assessments in 6 countries including UWEZO in Kenya, Tanzania and Uganda. Their evaluation focussed on their "ability to measure learning, collect robust data, and stimulate awareness and action". There were three key questions (answered with the methods in italics and parentheses):

"1. How well do citizen-led assessments measure learning? Technical review of the testing tools, sampling design, and analytical processes used.

2. How well do citizen-led assessment processes work? Process evaluation

3. How well do citizen-led assessments stimulate awareness and action about learning outcomes? Non-experimental evaluation of impact." (R4D, 2014)

Many of their conclusions and recommendations seem appropriate but, their analysis of the validity of their learning data and of their sampling processes have missed out one of the most important issues, viz., their coverage of the population of children, which of course affects the literacy rates estimated from UWEZO household-based data compared with school-based assessments. The hypothesis being examined in this paper is that citizen-led surveys provide better coverage of the hard-to-reach poorer areas or population groups. This could be either because their locally-based enumerators are more likely to be aware of recent changes or movements in the local population composition/ distributions such as the immediately current location of nomadic groups and their watering holes; and/ or more able to move in security-sensitive areas because of their local contacts; and/ or because the standardised household surveys usually use only one enumerator, whilst the citizen based surveys always use two enumerators. 


\section{II: COMPARING THE COVERAGE OF CITIZEN-LED SURVEYS WITH DHS}

The only possible external recent national comparison source in these three countries is with the DHS International Standardised Surveys ${ }^{4}$. Whilst the DHS survey does include a question on whether or not the child is enrolled and is attending, the interest here is in more direct measures of poverty. The UWEZO household questionnaires include some asset-type questions, so that we are able to estimate the coverage of access to clean / piped water and to improved sanitation. For both of these (the rates of improved water and sanitation, as well as of literacy), it has usually been assumed (e.g. by the United Nations Development Programme for providing data to measure the achievement of the Millenium Development Goals) that reasonable estimates can be derived either from DHS or MICS surveys; and this is also the assumption inherent in the New Data Revolution's focus on better data quality and consistency, rather than on querying the basic fidelity of the sources themselves (UN, 2015b). But, as we have outlined in section 1.3, there are a priori reasons for doubting the coverage of international standardised household surveys, and in section 1.4 that there are also a priori reasons for suspecting that citizen-led assessments may achieve better coverage; and that the differences may well be differentially geographically distributed. This is explained in the following sub-section.

\section{II.1 Which Groups Might be Differentially Covered?}

Thus, in comparing the DHS and UWEZO survey, it is probably safe to assume that there will be no systematic difference between the two surveys, which are both household-based, in respect of the homeless and those in institutions (categories 1 and 2). There could, however, be differences in respect of the coverage of mobile and nomadic populations (category 3), in respect of those in fragile households, insecure areas, older women (categories 4, 6 and 7), those in urban slums (category 5) and of servants (category 8). The UWEZO survey focussed on children will not attempt to count older women or servants/ 'slaves' in households. The four remaining categories of nomadic areas (category 3), fragile households (category 4), urban slums (category 5) and insecure areas (category 6) will however be relevant for most countries in Sub-Saharan Africa. 
It is difficult to make even primitive estimates of the number of fragile households but, making the quite strong assumption that most would be linked to HIV, this would lead to an across-the board under-counting, given that the epidemic is now mature in all three countries. Provinces or regions that are insecure are well-known, although the precise distribution of insecurity at a local level will require specific local knowledge, which cannot easily be summarised. The following sub-subsections focus therefore only on nomadic groups and urban slums.

\section{Nomadic Groups in the three countries}

For the three countries in East Africa, we know that there are large concentrations of nomads in certain areas. In 2000, the estimated number of nomads and their percentage of the national population (Author et al, 2005) were: in Kenya 7.5 million (25\%), Tanzania 6.0 million (19\%) and in Uganda, 1.03 million (5\%), although some would argue that these numbers have reduced in recent years.

Randall (2015) presents census data, mainly for West African countries, showing that, as a proportion of the national population, they have declined substantially over the last 50 years. She also argues that, for many countries in Africa, the censuses do make considerable efforts to include the pastoralists and recent improvements suggest that there is some hope for the denominators required by the SDGs. But this misses the point; the majority of estimates of poverty are derived from household surveys which, as she also demonstrates in her Table 2, either explicitly omit nomadic areas or are unclear.

\section{Urban Slums}

The slums of Nairobi, notably Kibera, are perhaps the best known but are not the largest in East Africa according to UN Habitat (2013) which estimates Tanzania to have the largest population of slum-dwellers at 7.2 million, 50\% more than those in Kenya (4.762 million) even though the capital of Kenya is larger than that of Tanzania both in absolute size and relative to the total population. Uganda is the least urbanised of the three countries. 


\section{TABLE 1 ABOUT HERE}

\section{II.2 Comparing the Questions in the Two Surveys}

But before considering the possibilities of difference in 'coverage' in detail, we should ask whether there are any differences in the way in which the question was asked in the two surveys. For electricity, UWEZO asks whether the household has 'Access to' whilst DHS asks whether the household 'Has'; one might therefore expect the values to be higher in the UWEZO survey - because 'Access' might for example include access via a neighbour - and, in general, they are (the differences, 'DHS-UWEZO', are negative). For bicycle and radio, UWEZO asks whether the household 'Owns' whilst DHS asks whether the household 'Has'; but whilst one might have access to a bicycle or radio without owning it, ownership does not necessarily imply that the bicycle or radio are functioning, so it is difficult to make a prediction either way - and, in general, there are no systematic differences. It is therefore difficult to draw any conclusions from these comparisons.

It is therefore important to find a variable where at least the question appears to be equivalent ${ }^{5}$. The most promising appears to be availability of clean water but even here there are complications.

The DHS questionnaire always ask the Source of Water with a large number of answer codes which they categorise into Improved Source (including water piped into dwelling / yard /plot, shared tap, public tap; tube well or borehole, neighbours' borehole; protected well in dwelling/ yard/ plot, protected public well, protected spring; rainwater) and Unimproved Source. The UWEZO questions vary between countries (see Box 1) and require some manipulation.

Thus, in Kenya, in both DHS and UWEZO, we can calculate a new variable 'near clean water': by combining in DHS those reporting clean water in dwelling, yard or plot, and in UWEZO those reporting source of water at home, with (in both surveys) those who take less than 30 minutes to fetch water; in Tanzania, noting that the questionnaire says 'Do you have access to piped water', we use in DHS those reporting piped or tap water in dwelling, yard or plot, with neighbour or public; we have not included tube or borehole access; and in Uganda, the only possibility ${ }^{6}$ was to compare those 
reporting clean water in dwelling, yard or plot in DHS with those in UWEZO reporting less than 15 metres to clean water..

BOX 1 UWEZO questions on Water

\begin{tabular}{|l|l|}
\hline KENYA & (a) source of water at home; (b) if not, time taken to fetch water \\
\hline TANZANIA & 'direct access to clean water' \\
\hline UGANDA & Distance to the nearest clean water source \\
\hline
\end{tabular}

\section{III: DESIGN OF SURVEYS AND THEIR COVERAGE OF VULNERABLE GROUPS}

\section{III.1 Demographic and Health Surveys}

\section{KENYA}

The sampling frame for the Kenya 2008-09 DHS is based on the enumeration areas (EAs) covered in the 1999 population and housing census, which was based on the master sampling frame developed by KNBS, although some clusters were updated. So, even assuming perfect census coverage, in general, the coverage of settlements in the sampling frame of the 2008-09, KDHS is ten years old. Also, fewer households and clusters were surveyed by KDHS in North Eastern province, compared with the other provinces, because of its sparse population. A deliberate attempt was made to oversample urban areas to get enough cases for analysis (KDHS, 2008-09, p.8).

\section{TANZANIA}

The most recent DHS was in 2011-12. The sampling frame for the Tanzania 2010 DHS is based on the EAs covered in the 2002 population and housing census (TDHS, 2011, p.6). So, even assuming perfect census coverage, the coverage of settlements in the sampling frame of the 2010 TDHS is eight years old. The census excluded migratory EAs (Randall, 2015). 


\section{UGANDA}

The clusters used as the basis for sampling in the 2011 UDHS were selected from among a list of clusters sampled for the 2009/10 Ugandan National Household Survey; in turn those clusters were selected from the 2002 Population Census (UDHS, 2012, p.6). So, even assuming perfect census coverage, the coverage of settlements in the sampling frame of the 2011 UDHS is 9 years old.

For all three countries, the length of time between the sampling frame used for DHS and the surveys is around 10 years. There would have been a lot of development and, conversely, informal settlement during that period. (UN HABITAT, 2013).

\section{III.2 UWEZO}

Uwezo has a standards manual (UWEZO, 2012) that should be followed by all three national sampling teams. The pertinent extract is reproduced below:

\section{Box 3: UWEZO household survey: Sampling design and implementation}

Sampling for the Uwezo annual assessments shall be conducted by experts from the National Bureau of Statistics of the respective countries ii) The census frame shall constitute the basis of the sampling. The district shall be the main stratum, followed by 30 EAs/villages per district, and 20 households per village iii) The census frame and resource availability shall guide the treatment of the new districts. Where the new districts deviate from the census frame, old district boundaries shall be retained. Where the census frame has been respected, and subject to availability of funds, new districts shall be included iv) Each year, a rotational panel of 10 villages each shall be used for sampling v) District Coordinators/District Contact Persons shall sample the households in each village using household listing and thereafter selection based on the nth number. 
Kenya had a census in 2009 which would have been used by UWEZO; Tanzania was in 2012, later than the comparison year and so UWEZO would have used the 2002 census (like DHS); Uganda was in 2013 also later than the comparison year and so UWEZO would have used the 2002 census (like DHS). We might therefore expect the least difference between the two surveys with Kenya.

\section{III.3 Treatment of Nomadic groups and Urban Slum areas in the Sampling Frames}

\section{KENYA}

Nomadic Groups: Provinces with substantial number of pastoralists are North Eastern and Rift Valley $^{7}$

Slum Populations: Apart from the mention that urban areas were over-sampled, there is no specific reference to the problems of enumerating slum areas.

\section{TANZANIA}

Nomadic Groups: According to the methodology report for the 2002 census (p. 28), there were three types of enumeration area: i) normal EAs composed of private households; ii) special category EAs composed of collective households like hotels, hospitals, etc.; and iii) special category EAs capturing the migratory population settlements such as temporary camps of nomadic pastoralists, fishermen, honey collectors, etc. Later in that document (p. 52), the migratory population is defined as 'people who have no permanent living residence. They usually move from one living place to another. The reason for this could be that they are looking for new fishing areas, grazing ground etc. Before enumeration the DCEOs contacted their local leaders so as to make special arrangements on how to locate and enumerate such a population. All persons belonging to this category were enumerated where they spent the census night' (United Republic of Tanzania: Central Census Office, 2003). The recommendations in the same report (p. 44) suggests that in the future, the 'special category population, i.e. fishing camps, mining camps, nomadic populations etc. should be included in the sample design' and this was done for the 2012 census (United Republic of Tanzania, 2013). Thus, a 
number of mobile, and probably not so mobile, pastoralists were almost totally invisible in Tanzanian censuses from 1968 to 2002 .

Ten years ago, a review of education for nomads in Tanzania identified the following regions and the districts where they were mostly settled (Author et.al., 2005): these were in Arusha, Manyara, Morogoro, Pwani, Simyu and Singida regions ${ }^{8}$. About half of the districts are in the Arusha and Manyara regions. Tanzania does not ask about ethnicity in the census, which makes it difficult to estimate Maasai living in Tanzania but most of them would be in Arusha, Manyara and Mara.

Slum Populations: In Tanzania, slums and squatter settlements are defined by their National Statistical office as follows:

"Slums and Squatter Settlements: These are unplanned human settlements that lack modern services and basic socio-economic services such as roads, water supply, electricity, sewage and drainage systems. These are inhabited by low income earners with high household sizes."

The population numbers in slums in Tanzania is reported to be 6.2 million, or about two thirds of those in urban areas altogether (Centre for Community Initiatives, 2013); on the other hand, United Nations report an estimate of 92 percent of Tanzania's urban populations living in slum conditions, more than 11 million people, which would make it the third largest slum population in Africa.

\section{UGANDA}

Nomadic Groups: The districts in Uganda with substantial numbers of pastoralists are Kotido and Moroto in Karamoja Region with a total of 440,000, Nasongola in Central 2 Region with 340,000, Kalangala in Central 1 Region with 210,000.

Slum Population: the only city with a substantial slum population is Kampala, estimated at 2.5 million (UN Habitat, 2010/11); although there are smaller numbers in Arua, Jinja, Kabale Mbale and MbararNa totalling about 200,000 (McKau, Dobson and Samia, 2012).

\section{III.4 Statistical Analysis}


In the analysis, our statistic is the difference between sample means and our hypothesized value is 0 . The statistic is the difference between means, so the estimated standard error of the statistic is $\left(\mathrm{S}_{\mathrm{m} 1-}\right.$ $\left.{ }_{\mathrm{m} 2}\right)$. The formula for the standard error of the difference between means is: $\mathrm{O}_{\mathrm{m} 1-\mathrm{m} 2}=\mathrm{SQRT}\left(\mathrm{o} 1^{2} / \mathrm{n}_{1}+\right.$ $\left.\circ 2^{2} / \mathrm{n}_{2}\right)$, where o 1 and $\circ 2$ are the standard deviations of the two samples.

\section{IV: RESULTS}

Kenya: comparison of DHS 2008-09 with UWEZO 2011

The first UWEZO survey in Kenya was in 2011. The data set for 2011 does not appear to include an urban /rural variable so the only comparison is by region. The difference at national level is 8.0 percentage points for electricity and 31.6 percentage points for water (Table 2). Five of the regional differences for electricity are positive out of 8 (with one zero) and of those, all except one are statistically significant at the $0.1 \%$ level; and 7 of the differences for water are significantly positive out of 8 (and all of those are statistically significant at, at least, the $0.1 \%$ level).

\section{TABLE 2 ABOUT HERE}

TANZANIA: comparison of DHS 2010 and Tanzania UWEZO for 2011.

UWEZO did conduct a survey in 2010 but it was at a smaller scale and specifically did not include any samples from Arusha and Ruvuma, so we have used the UWEZO 2011 data. The differences for electricity, although tending to show that DHS finds more households without electricity, are very small; but the overall national difference for direct access to clean water, although not very large, is statistically significant (Table 3), and:

- In ten of the regions, the rate in DHS is lower than in the UWEZO Tanzanian survey, with substantial differences (over15 percentage points) in Dodoma, Mara and Ruvuma; but,

- In Arusha, Dar-es-Salaam and Pwani, the rates of those without access to piped water are considerably higher in the DHS (more than 30 percentage points) - and they are more than 20 
percentage points higher in Kilimanjaro and Manyara - than in the Tanzanian UWEZO survey.

\section{TABLE 3 ABOUT HERE}

It is important to recognise that Arusha, Dar-es-Salaam, Kilimanjaro, Manyara and Pwani are not typical regions of Tanzania: Dar-es-Salaam is the main city of Tanzania and has large slums with some overspill to Pwani; and Arusha, Kilimanjaro and Manyara are regions with quite large slum populations and relatively large proportion of nomadic (mobile) population.

To explore this further, we have in Table 4, first compared the results of the DHS and UWEZO surveys for urban and rural areas of the two regions (Arusha and Dar-es-Salaam) where the difference was over 30 percentage points; and, in the second set of two regions (Kilimanjaro, Manyara) where the difference was over 20 but less than 30 percentage points. It can be seen that the difference is:

- largest in the urban areas of Arusha, Dar Es Salaam, Manyara and Pwani; but

- higher in the rural areas of Arusha, Kilimanjaro and Pwani.

Both of these observations are consistent with what we know about the distribution of urban slums and of nomadic groups in Tanzania.

\section{TABLE 4 ABOUT HERE}

\section{UGANDA}

The Ugandan UWEZO data set for 2011 does not appear to include an urban /rural variable so the only comparison is by sub-region ${ }^{9}$. The difference at national level is 6.7 percentage points for electricity and 10.6 percentage points for water. For electricity, out of 10 comparisons, five of the differences for electricity are positive and four of them are statistically significant at the $0.1 \%$ level, and five are negative with only one of them significant at the $0.5 \%$ level; and 8 of the differences for 
water are significantly positive out of 10 (and all of those are statistically significant at, at the.1\% level). For access to clean water, 8 of the differences are positive and statistically significant at least at the $0.1 \%$ level; and of the two negative differences, only one is statistically significant at the $0.5 \%$ level.

TABLE 5 ABOUT HERE

\section{V: DISCUSSION AND IMPLICATIONS}

\section{Querying Comparability, Comprehensiveness, Stability and Validity of UWEZO estimates}

\section{Comparability}

The training procedures for UWEZO-type surveys are standardised within countries, and the process evaluation by R4D (2014) confirmed that their interview procedures were rigorous; however both may vary between countries, but not between the three countries considered here which are all managed by TWAWEZA (http://www.twaweza.org/go/uwezo). The sampling procedures are also generic but, as we have demonstrated for the three East African countries, may have different consequences in different countries (and this would be true for DHS and similar surveys as well). Nevertheless, outside these three countries, there may well be issues regarding cross-national comparisons between citizen-led and enumerator-led surveys.

\section{Comprehensiveness}

Another problem is that, because they rely on volunteers, it is highly unlikely that citizen-led surveys could ever substitute for DHS or similar surveys, simply because they could never be as comprehensive. This suggests complementarity rather than competition between the two different types of survey: UWEZO and similar citizen-led surveys should be encouraged to 
generate the top-line figures for deprivation and poverty and their distribution; whilst DHS and similar surveys, which need not be as large-scale as currently, should be preferred for understanding the factors associated with poverty.

\section{$\underline{\text { Stability and Validity of In-Country Estimates }}$}

It might be thought that the UWEZO surveys are unstable in the sense of obtaining different values over time; we show the comparative rates for 2011 and 2012 in Table 6 and, in general, the withincountry year-on-year comparisons are not statistically different. Given that the DHS surveys are roughly every five years, there is no point in similar tabulations.

\section{Extrapolations for Three Capital Cities}

for Nairobi: The Nairobi population according to the 2009 Census was 3.138 million; according to the DHS estimate $86.5 \%$ had access to piped water compared to the UWEZO estimate of $70.2 \%$. If we assume that the census and UWEZO figures are correct then the DHS survey is only representing (i.e. including in its sampling frame) 2.547 million of that population; if we believe that the DHS is a representative sample of the census, then the UWEZO figure tells us that that the correct population of Nairobi is 3.867 million. The difference is 1,320 million.

For Dar Es Salaam: The Dar Es Salaam population according to the 2012 Census was 4.364 million; according to the DHS estimate 0.669 had access to piped water compared to the UWEZO estimate of 0.360. If we assume that the census and UWEZO figures are correct then the DHS survey is only representing (i.e. including in its sampling frame) 2,087 of that population; if we believe that the DHS is a representative sample of the census, then the UWEZO figure tells us that that the correct population of Dar Es Salaam is 8,537. The difference is 6.450 million.

For Kampala: The Kampala population according to the 2012 Census was 1,516 million; according to the DHS estimate 0.79 had access to piped water compared to the UWEZO estimate of 0.68 . If we assume that the census and UWEZO figures are correct then the DHS survey is only representing (i.e. 
including in its sampling frame) 1,305 million of that population; if we believe that the DHS is a representative sample of the census, then the UWEZO figure tells us that that the correct population of Kampala is 1,717 million. The difference is 0.412 million.

\section{Conclusions}

The UWEO estimates are stable across the years. The differences between the estimated capital city population sizes, depending on whether one believes the DHS or the UWEZO estimates of access to piped water, are very large and, even though one expects two surveys to reach different results (which can sometimes be statistically significant), difficult to believe; and for some of the other regions they would have, in relative terms, been larger. If we had used access to/has electricity as the marker indicator; the differences would have been smaller but still substantial for Nairobi and Kampala. If we take the lowest estimate of the percentage missing from DHS of $14 \%$ in Kampala then, taking the UN Habitat estimated population of 2.634 billion in urban areas of developing countries in 2012 as accurate, an estimated 369 million are missing from the DHS survey sampling frames in urban areas. The estimate of the numbers missing would be (much) higher if the estimates of percentages missing from Dar es Salaam and Nairobi are used; but we don't know the correct percentage missing: the correct value is probably somewhere in the middle.

Data has informed several policy concerns in developing countries including not only access to water but also immunization coverage, nutritional status and the out-of-school problem (Muwonge, 2006). The underestimate of deprivation indicators would tell policy makers that the situation is worse than they thought; it would probably not affect the weight they place on different dimensions of poverty.

It is very important for the UN Data Revolution and for the attempt to 'Leave No One Behind' to find out which is the better estimate, by how much and why. A first step would be to examine not only the possibilities of different meanings being attached to apparently the same questions and the different approaches to sampling (two desk-based exercises) but also the different approaches to ensuring responses and to interviewing (which would require interviewing and following the enumerators in the two sets of surveys). 
Looking further afield, all countries should be helped to put in place quality Civil Registration and Vital Statistics (CRVS) systems which, if the procedure is well organised can be relatively inexpensive, although of course there are annual maintenance costs. An alternative approach are the Community-Based Monitoring System (CBMS) project, started in the Philippines and now implemented in 22 countries across Africa, Asia and Latin America, entails community members and local officials tracking poverty and development issues at household level. This information has proved crucial in many places for local budgeting interventions addressing specific group needs (see Partnership for Economic Policy, 2011).

The main message is that, if we cannot count the poorest groups of the population, then poverty reduction programmes are unlikely to be successful. It is urgent to learn how to count. 


\section{ENDNOTES}

1 The only household visits were those of the routine annual Labour Force Surveys.

2 See also Carr-Hill (2015) based on a presentation in Vancouver in 2013.

3 Perhaps because of their omnipresence in statistical based publications

4 There was a UNICEF Multiple indicator Cluster Survey (MICS) in Tanzania in 1996, and there have been a series of county and province level MICS in Kenya in the last few years but no national survey.

5 There can easily be undocumented differences in the training of the interviewers and therefore the implementation of the surveys.

6 We considered but rejected estimating time taken to walk 1 kilometre when going and returning, because of the variety of terrain in the three countries.

7 Districts with substantial numbers of pastoralists are: Baringo, Marakwet, Mt. Elgon, Nakuru, , Kaijado, Narok, Samburu, Transmara, Turkana, W. Pokot (in Rift Valley province); Isiolo, Marsabit, Moyale (in Eastern Province); Garissa, Mandera, Wajir (in North Eastern province); and Tana River (in Coast Province). So we expect North Eastern and Rift Valley provinces to be most affected; and the Maasai in Kenya are in the Southern part of the Rift Valley.

8 Manyara, Arusha, Monduli, Ngororongo (in Arusha Region); Kiteto, Mbulu, Simanjiro (in Manyara region); Iramba, Singida (in Singida Region); Kilosa, Morogoro in (Morogoro region); Bagamoyo (in Pwani Region); Meatu (in Simiyu Region); Serengeti (in Mara Region); and Tabora (in Tabora Region) .

$9 \quad$ This required some manipulation to create sub-regions within the UWEZO data set which had used 77 districts as the basis for their analysis rather than the 110 districts used in the DHS data sets. 


\section{REFERENCES (AND SOURCES)}

Abbasi-Shavazi, M. J., \& Sadeghi, R. (2011). The adaptation of second-generation Afghans in Iran: Empirical findings and policy implications. Middle East Institute - Fondation de la Recherche Strategique Retrieved (c) November 30th 2012. Available from http://www.refugeecooperation.org/publications/Afghanistan/05_jalal.php.

Agarawal, S. (2011). 'The state of urban health in India; comparing the poorest quartile to the rest of the urban population in selected states and cities'. Environment and Urbanization, 23(1), 13-28

Alkire, S. and Samman, E. (2014) Mobilising the household data required to progress towards the SDGs. Oxford: Oxford Poverty and Human Development Initiative

Anti-Slavery (2015) Domestic Work and Slavery http://www.antislavery.org/english/slavery today/domestic work and slavery/default.aspx

Berner, E. (1997). Defending a place in the city: Location and the struggle for Urban land in Metro Manila. Dissertation, Quezon City: Ateno de Manila University Press

Buettner, T., \& Garland, P. (2008). Preparing population estimates for all countries of the world: Experiences and challenges. Presentation to Committee for the Coordination of Statistical Activities, Rome

Author (2013) 'Missing Millions and Measuring Development Progress', World Development, 46 (June), pp 30-44; http://dx.doi.org/10.1016/j.worlddev.2012.12.017

Author in collaboration with Eshete, A, Sedel, C. and de Souiza, A. (2005) The education of Nomadic Peoples in East Africa: Synthesis report: Djibouti, Eritrea, Ethiopia, Kenya, Tanzania and Uganda. UNESCO-IIEP and African Development Bank.

Author (2014) Measuring development progress in Africa; the denominator problem Canadian Journal of Development Studies/ Revue canadienne d'études du développement, 35 (1); pp.136154; http://dx.doi.org/10.1080/02255189.2014.884969 
CARDO (Centre for Architectural Research and Development Overseas) (2003) The nature and extent of homelessness in developing countries. DFID Project No. 7905.

Chan, M., Kazatchkine, M., Lob-Levyt, J., Obaid, T., Schweizer, J., et al. (2010). 'Meeting the demand for results and accountability: A call for action on health data from eight global health agencies'. PLoS Med., 7(1). http://dx.doi.org/10.1371/journal.pmed.1000223.

Chandrasekhar, S. (2005). Growth of slums, availability of infrastructure and demographic outcomes in slums: Evidence from India. Paper presented during the session on Urbanization in Developing Countries at the Population Association of America, 2005, Annual Meeting, Philadelphia, USA.

Committee on Protection of Tribal Areas in the North East (COPTAM) (2011). Retrieved October 30th 2012. Available from http:// www.indigenousportal.com/Politics/Northeast-India-COPTAMUnpleasant-tidings-greet-Census-2011.html.

Davis, M. (2006). Planet of slums. London and New York: Verso, p. 26.

Demographic and Health Survey (DHS) (2010) Kenya DHS, 2008-09 - Final Report (English), FR229

Demographic and Health Survey (DHS) (2011) Tanzania DHS, 2010 - Final Report (English), FR243

Demographic and Health Survey (DHS) (2012)_Uganda DHS, 2011 - Final Report (English) FR264

Di, W. (2011). 'Door-to-door census needs more accountability'. Global Times. September 10th. Beijing: People's Daily.

Dwinosumono, S. (2006). The population census in Indonesia. Presented at fifth management seminar for the Heads of National Statistical Offices in Asia and the Pacific, Daejon, Republic of Korea.

Foster, G. (2000). 'The capacity of the extended family for orphans in Africa'. Psychology, Health \& Medicine, 5, 55-62

Gill, M. S. (2007). 'Politics of population census data in India'. Economic and Political Weekly, 241249. 
Independent Expert Advisory Group on a Data Revolution for Sustainable Development (IEAG) (2014) A World that Counts Mobilising the Data Revolution for Sustainable Development, UN Joloza, T. (2009). Non-Household Groups: Position Paper, London: Office of National Statistics.1 Kalipeni, E., Craddock, S., Oppong, J. R., \& Ghosh, J. (Eds.) (2004). HIV \& AIDS in Africa: Beyond epidemiology. Malden, MA: Blackwell Publishing

Maligalig, D. S., \& Martinez, A. Jr (2013). 'Developing a Master Sample Design for Households Surveys in Developing Countries: A Case Study In Bangladesh'. Survey Methods: Insights from the Field. Retrieved from http://surveyinsights.org/?p=2151

McCarthy, P. (2003). Urban slums reports: The case of Jakarta, Indonesia. In Understanding slums: Case studies for the global report on human settlements. New York: UN Habitat

McKau, J., Dobson, S. and Samia, E. (2012) 'The five-city enumeration: the role of participatory enumerations in developing community capacity and partnerships with government in Uganda' Environment and Urbanisation, vol. 24, no 1, pp.31-46

Mishra, V., Barrere, B., Hong, R., \& Khan, S. (2008). 'Evaluation of bias in HIV seroprevalence estimates from national household surveys'. Sexually Transmitted Infections, 84 (Suppl. 1), i63i70. http:// dx.doi.org/10.1136/sti.2008030411.

Misra, P. K., \& Malhotra, K. C. (Eds.) (1982). Nomads in India: Proceedings of the National Seminar. Calcutta: Anthropological Survey of India.

Montgomery, M. (2009). 'Urban poverty and health in developing countries'. Population Bulletin, 64, 2

Morphy, F. (2007) 'Uncontained subjects: Population and household in remote aboriginal Australia', Journal of Population Research, 24 (2), pp 163-184

Muwonge, J. (2006) 'The Role of Household Surveys in Poverty Reduction Efforts: A Case of the Uganda National Household Survey Programme', The African Statistical Journal, 3, pp.111-134. Office of National Statistics (2016) Annual Mid-Year Population Estimates, Quality and Methodology Information, London: ONS. 
Partnership for Economic Policy (2011) Country Project Profiles (www.pep-net.org/country-projectprofiles), Nairobi: PEP Global Office.

Passel, J. S. and Cohn, D'V. (2010). U.S. unauthorized immigration flows are down sharply since mid-decade. Washington: PEW Hispanic Centre.

Patel, S. (1990). 'Street children, hotels boys and children of pavement dwellers and construction workers in Bombay: how they meet their daily needs'. Environment and Urbanization, 2(2), 9-26.

Pempel, T. J. (2011). 'In search of a common denominator'. Economist, Bangkok, March 17th. Retrieved November $\quad 30^{\text {th }}$. http://www.economist.com/blogs/banyan/2011/03/bangladeshs_census.

Peressini, T., Mcdonald, L., \& Hulchanski, D. J. (2010). 'Towards a strategy for counting the homeless'. in D. J. Hulchanski, P. Campsie, S. B. I. Chau, Hwang, \& E. Paradids (Eds.), Finding home: Policy options for addressing homelessness in Canada. Toronto: Cities Centre, University of Toronto.

Pettersson, H. (2005) Design of master sampling frames and master samples for household surveys in developing countries, Chapter V in Household Sample Surveys in Developing and Transition Countries. Stockholm, Sweden: Statistics Sweden

Pincus, J., \& Sender, J. (2008). 'Quantifying poverty in Viet Nam: Who counts?'. Journal of Vietnamese Studies, 3(1), 108-150

Plaut, D. and Eberhardst, M.J. (2015) Bringing Learning to Light: The role of citizen-led assessments in shifting the education agenda. Washington: Results for Development Institute

Powell, N. P. (1981). Major obstacles to achieving satisfactory registration of vital events and the compilation of reliable vital statistics. Technical papers of the International Institute for Vital Registration and Statistics, No 15. Bethesda, MD: International Institute for Vital Registration and Statistics.

Randall, S. (2015) 'Where have all the nomads gone? Fifty years of statistical and demographic invisibilities of African mobile pastoralists', Pastoralism: Research, Policy and Practice, 5:22; DOI 10.1186/s13570-015-0042-9 
Randall, S. and Coast, E. (2016) 'The quality of demographic data on older Africans', Demographic Research, 34, 143-174 http://www.demographic-research.org/Volumes/Vol34/5/ DOI: 10.4054/DemRes.2016.34.5.

Refugees International (2007). About being without: Stories of stateless in Kuwait. Washington: Refugees International.

Richter, L. M., \& Desmond, C. (2008). 'Targeting AIDS orphans and child-headed households? A perspective from national surveys in South Africa, 1995-2005'. AIDS Care, 20(9), 1019-1028.

Rigg, J. (1991). Southeast Asia: A region in transition. London: Routledge.

Sabry, S. (2010). 'How poverty is underestimated in Greater Cairo, Egypt'. Environment and Urbanization, 22(2), 523-541.

Sankoh, O. and Byass, P.(2012) The INDEPTH Network: filling vital gaps in global epidemiology, Int J Epidemiol. 2012 Jun; 41(3): 579-588. doi: 10.1093/ije/dys081

Setel, P., Macfarlane, S., Szreter, S., Mikkelsen, L., Prabhat, J., Stout, S., et al. (2007). 'A scandal of invisibility: Making everyone count by counting everyone'. The Lancet, 370(9598), 1569-1577.

Sri Lanka Ministry of Finance and Planning (2009) Poverty in Sri Lanka, Department of Census and Statistics

Statistics Canada (2015) Population and Family Estimation Methods at Statistics Canada http://www.statcan.gc.ca/pub/91-528-x/2011001/ch/ch1-eng.htm

Statistics Netherlands (2012) 'The Dutch Virtual Census'. Video: http://youtu.be/SLpDkcyenf0.

Stuart, E., Samman, E., Avis, W. and Berliner, T. (2015) The data Revolution: finding the missing millions, Overseas Development Institute, Research Reports no 3.

Szreter, S., H. Sholkamy and A. Dharmalingam (eds). (2004).Categories and Contexts: Anthropological and Historical Studies in Critical Demography. Oxford: Oxford University Press. 
Thornton, P. K., Kruska, R. L., Henninger, N., Kristjanson, P. M., Reid, R. S., Atieno, E., et al. (2003). Mapping poverty and livestock in the developing world. Nairobi: International Livestock Research Institute

UN (2015a) Principles and Recommendations for Population and Housing Censuses Revision 3 Department of Economic and Social Affairs Statistics Division, Statistical papers, Series M, No. 67/Rev.3

UN Data Revolution Group (2015b) A World that Counts: Mobilising the Data Revolution for Sustainable Development, New York, UN Independent Expert Advisory Group

UN (2016a) Population and Housing Censuses

http://unstats.un.org/unsd/demographic/sources/census/alternativeCensusDesigns.htm.

UN (2016b) Methodology and Lessons Learned to evaluate the completeness and quality of vital statistics from civil registration http://www.un.org/en/development/desa/population/events/expert-group/26/index.shtml.

UN Habitat (2013) State of the World's Cities: The Prosperity of Cities, New York.

UNHCR (2015) Global Trends: Forced Displacement in 2015, Geneva.

UWEZO Tanzania (2011). Our Children are still not learning: Annual Assessment Report, Dar es Salaam, Uwezo, TENMT and Hivos.

UWEZO (2011) Are our Children Learning? Numeracy and Literacy Across East Africa 2011, Nairobi, Uwezo\&Hivos

Valente, P. (2010). 'Census-taking in Europe: How are populations counted in 2010'. Population and Societies, 467.

Villegas, C.C. and Samman, E. (2015) Exclusion in household surveys Causes, impacts and ways forward, Oversea Development Institute

Vlahov, D., Agarwal, S. R., Buckley, R. M., Caiaffa, W. T., Corvalan, C. F., Ezeh, A. C., et al. (2011). 'Roundtable on urban living environment research (RUL)'. Journal of Urban Health, 88(5), 793-857. 
Walmsley, R. (2003). World Prison Population List (4th ed). Home Office, Research Paper Findings 188

Watkins, K. and Alemayehu, W. (2012) Financing for a fairer, more prosperous Kenya: a review of the public spending challenges and options for selected arid and semi-arid counties. Washington, Brookings

World Bank (2010) World Bank Updates Poverty Estimates for the Developing World. http://econ.worldbank.org/WBSITE/EXTERNAL/EXTDEC/EXTRESEARCH/0,, contentMDK:2 1882162 pagePK:64165401 piPK:64165026 theSitePK:469382,00.html

World Bank/WHO (2014) Global civil registration and vital statistics: scaling up investment plan 2015-2024. Washington DC: World Bank.

Zimba, J., \& Tembo, B. (2007). 'Women have to cope as AIDS, economic woes afflict Zambia', ISIS International. Monday, 04 June, Retrieved November 30th. Available from http://www.isiswomen.org/ index.php?option=com_content\&task=view\&id=713\&Itemid=200. 
Table 1: Urban and Slum Populations around 2012

\begin{tabular}{|l|l|l|l|l|l|l|}
\hline & Total & Urban & Slum & As \% of Total & Population of & As \% of Total \\
& Population & Population & Population \\
$(2012)$ & Population & Largest City & Population \\
$(2012)$ & & & & \\
\hline Kenya & 43,180 & 9,064 & 4,762 & 11.0 & 4,303 & 10.0 \\
\hline Tanzania & 47,780 & 11,883 & 7,200 & 15.1 & 4,153 & 8.7 \\
\hline Uganda & 36,350 & 4,493 & 2,578 & 7.1 & 1,982 & 5.5 \\
\hline
\end{tabular}

Source: UN Habitat (2013) State of the World's Cities: The Prosperity of Cities 
Table 2: KENYA: Comparing DHS 2008-2009 (11/08-02/09) and UWEZO 2011 Estimates of Access to Nearby Clean Water and to Electricity

\begin{tabular}{|c|c|c|c|c|c|c|c|}
\hline & & \multicolumn{2}{|r|}{ DHS } & \multicolumn{2}{|r|}{ UWEZO } & \multicolumn{2}{|c|}{ Difference DHS-Uwezo } \\
\hline & & Electricity & Water & Electricity & Water & Electricity & Water \\
\hline \multirow[t]{3}{*}{ Nairobi } & Mean & 87 & 86.5 & 71 & 70.2 & 16 & 15.3 \\
\hline & $\mathrm{N}$ & 1108 & 1108 & 6232 & 473 & $* * *$ & *** \\
\hline & Std. Dev. & 0.331 & 0.343 & 0.455 & 0.458 & & \\
\hline \multirow[t]{3}{*}{ Central } & Mean & 22 & 57.1 & 36 & 60.6 & -14 & -3.5 \\
\hline & $\mathrm{N}$ & 1133 & 1134 & 18985 & 11989 & $* *$ & $* *$ \\
\hline & Std. Dev. & 0.415 & 0.495 & 0.479 & 0.489 & & \\
\hline \multirow[t]{3}{*}{ Coast } & Mean & 0.31 & 66.1 & 19 & 19.8 & 12 & 46.3 \\
\hline & $\mathrm{N}$ & 1212 & 1212 & 13684 & 12969 & $* *$ & $* * *$ \\
\hline & Std. Dev. & 0.463 & 0.474 & 0.394 & 0.398 & & \\
\hline \multirow[t]{3}{*}{ Eastern } & Mean & 10 & 48.3 & 12 & 16.9 & -2.0 & 31.4 \\
\hline & $\mathrm{N}$ & 1236 & 1237 & 23326 & 24133 & - & *** \\
\hline & Std. Dev. & 0.294 & 0.500 & 0.324 & 0.375 & & \\
\hline \multirow[t]{3}{*}{ Nyanza } & Mean & 0.13 & 48.5 & 7 & 17.5 & 6 & 31.0 \\
\hline & $\mathrm{N}$ & 1313 & 1314 & 19695 & 19805 & *** & *** \\
\hline & Std. Dev. & 0.335 & 0.500 & 0.252 & 0.380 & & \\
\hline \multirow[t]{3}{*}{ Rift Valley } & Mean & 0.15 & 48.8 & 15 & 28.3 & 0 & 20.5 \\
\hline & & 1357 & 1357 & 47900 & 51401 & - & *** \\
\hline & & 0.357 & 0.500 & 0.356 & 0.451 & & \\
\hline \multirow[t]{3}{*}{ Western } & Mean & 9 & 55.2 & 6 & 19.3 & 3 & 35.9 \\
\hline & $\mathrm{N}$ & 1060 & 1061 & 16831 & 20170 & $*$ & $* * *$ \\
\hline & Std. Dev,. & 0.283 & 0.497 & 0.236 & 0.395 & & \\
\hline \multirow[t]{3}{*}{ North East } & Mean & 13 & 33.0 & 7 & 15.4 & 6 & 17.6 \\
\hline & $\mathrm{N}$ & 634 & 634 & 8280 & 13992 & $* *$ & *** \\
\hline & Std. Dev. & 0.334 & 0.470 & 0.249 & 0.361 & & \\
\hline \multirow[t]{3}{*}{ Total } & Mean & 25 & 56.3 & & 24.7 & 8 & 31.6 \\
\hline & $\mathbf{N}$ & 9053 & 9057 & & 154932 & $* * *$ & $* * *$ \\
\hline & Std. Dev, & 0.433 & 0.49607 & & 0.4311 & & \\
\hline
\end{tabular}

Source: Authors calculation from DHS 2008/09 and UWEZO Kenya 2011 (EARLIEST

AVAILABLE) 
Table 3: TANZANIA: COMPARISON UWEZO 2010 WITH DHS 2010 (fieldwork 12/09.

05/10)) FOR BASIC AND MODERN ASSETS:

\begin{tabular}{|c|c|c|c|c|c|c|c|c|c|}
\hline \multirow{4}{*}{$\begin{array}{l}\text { District (DHS } \\
\text { sample size) }\end{array}$} & & \multicolumn{8}{|c|}{ BASIC ASSETS } \\
\hline & & \multicolumn{3}{|c|}{ Household \& electricity } & \multicolumn{5}{|c|}{ Household has direct access to clean water } \\
\hline & & \multirow{2}{*}{\begin{tabular}{|l|} 
'Has' \\
DHS \\
\end{tabular}} & \multirow{2}{*}{\begin{tabular}{|l|} 
'Access' \\
Uwezo
\end{tabular}} & \multirow{2}{*}{$\begin{array}{l}\text { DHS - } \\
\text { Uwezo }\end{array}$} & \multirow[t]{2}{*}{ Uwezo } & \multicolumn{2}{|c|}{ DHS } & \multicolumn{2}{|c|}{ DHS-Uwezo } \\
\hline & & & & & & Tap & Tap+tube & Tap & Tap+tube \\
\hline Arusha & Mean & 0.21 & 0.23 & -0.02 & 43.0 & 70.7 & 73.9 & 27.7 & 30.9 \\
\hline$(340)(411)$ & Std. Dev. & 0.340 & 0.423 & & 0.495 & 0.456 & 0.440 & $* * *$ & \\
\hline Dar-es-Salaam & Mean & 0.68 & 0.64 & 0.04 & 32.0 & 47.7 & 66.9 & 15.7 & 34.9 \\
\hline$(521)(730)$ & Std. Dev. & 0.467 & 0.479 & & 0.465 & 0.500 & 0.471 & $* *$ & \\
\hline Dodoma & Mean & 0.07 & 0.13 & -0.04 & 41.0 & 25.5 & 25.5 & -15.5 & -15.5 \\
\hline$(345)(580)$ & Std. Dev. & 0.411 & 0.332 & & 0.491 & 0.436 & 0.436 & $* * *$ & \\
\hline Iringa & Mean & 0.11 & 0.19 & -0.08 & 34.0 & 39.3 & 41.2 & 5.3 & 7.2 \\
\hline$(343)(498)$ & Std. Dev. & 0.311 & 0.389 & & 0.472 & 0.489 & 0.493 & $* *$ & \\
\hline Kagera & Mean & 0.07 & 0.10 & \begin{tabular}{|c|}
-0.03 \\
\end{tabular} & 16.0 & 11.2 & 13.2 & -4.8 & -2.8 \\
\hline$(344)(556)$ & Std. Dev. & 0.261 & 0.298 & & 0.367 & 0.316 & 0.319 & $N S$ & \\
\hline Kigoma & Mean & 0.05 & 0.09 & -0.04 & 31.0 & 27.7 & 29.0 & -3.3 & -2.0 \\
\hline$(351)(417)$ & Std. Dev. & 0.215 & 0.285 & & 0.464 & 0.448 & 0.454 & $N S$ & \\
\hline Kilimanjaro & Mean & 0.20 & 0.26 & -0.06 & 44.0 & 64.0 & 65.6 & 20.0 & 21.6 \\
\hline$(341)(460)$ & Std. Dev. & 0.400 & 0.441 & & 0.496 & 0.481 & 0.476 & $* * *$ & \\
\hline Lindi & Mean & 0.10 & 0.10 & 0 & 13.0 & 8.3 & 9.3 & -4.7 & -3.7 \\
\hline$(351)(219)$ & Std. Dev. & 0.304 & 0.299 & & 0.338 & 0.277 & 0.292 & $* *$ & \\
\hline Mara & Mean & 0.09 & 0.14 & -0.05 & 35.0 & 20.1 & 21.1 & -15.0 & -13.9 \\
\hline$(342)(326)$ & Std. Dev. & 0.318 & 0.348 & & 0.447 & 0.401 & 0.409 & $* * *$ & \\
\hline Manyara & Mean & 0.11 & 0.12 & -0.01 & 11.0 & 40.2 & 40.9 & 29.2 & 29.9 \\
\hline$(345)(233)$ & Std. Dev. & 0.216 & 0.328 & & 0.313 & 0.491 & 0.493 & $* * *$ & \\
\hline Mbeya & Mean & 0.09 & 0.16 & -0.07 & 28.0 & 46.0 & 46.7 & 18.0 & 18.7 \\
\hline$(349)(591)$ & Std. Dev. & 0.289 & 0.367 & & 0.448 & 0.499 & 0.499 & $* * *$ & \\
\hline Morogoro & Mean & 0.12 & 0.17 & -0.05 & 38.0 & 33.9 & 34.7 & -4.1 & -3.3 \\
\hline$(338)(499)$ & Std. Dev. & 0.323 & 0.372 & & 0.486 & 0.474 & 0.477 & $*$ & \\
\hline Mtwara & Mean & 0.04 & 0.09 & -0.02 & 20.0 & 22.1 & 24.9 & 2.1 & 4.9 \\
\hline$(343)(425)$ & Std. Dev. & 0.205 & 0.286 & & 0.402 & 0.416 & 0.433 & $N S$ & \\
\hline Mwanza & Mean & 0.16 & 0.14 & 0.02 & 22.0 & 28.7 & 30.0 & 6.7 & 8.0 \\
\hline$(337)(699)$ & Std. Dev. & 0.365 & 0.348 & & 0.413 & 0.452 & 0.459 & $N S$ & \\
\hline Pwani & Mean & 0.16 & 0.15 & 0.01 & 19.0 & 51.6 & 52.2 & 32.6 & 33.2 \\
\hline$(312)(269)$ & Std. Dev. & 0.370 & 0.355 & & 0.391 & 0.501 & 0.500 & & \\
\hline Rukwa & Mean & 0.07 & 0.12 & -0.05 & 18.0 & 19.1 & 22.1 & 1.1 & 4.1 \\
\hline$(339)(278)$ & Std. Dev. & 0.252 & 0.326 & & 0.383 & 0.394 & 0.416 & & \\
\hline Ruvuma & Mean & 0.08 & 0.12 & \begin{tabular}{|c|}
-0.04 \\
\end{tabular} & 51.0 & 31.9 & 33.9 & -19.1 & -17.1 \\
\hline$(351)(361)$ & Std. Dev. & 0.271 & 0.324 & & 0.500 & 0.467 & 0.474 & & \\
\hline Shinyanga & Mean & 0.06 & 0.11 & -0.05 & 25.0 & 13.3 & 14.8 & -11.7 & -10.2 \\
\hline$(277)(607)$ & Std. Dev. & 0.240 & 0.307 & & 0.436 & 0.340 & 0.356 & & \\
\hline
\end{tabular}




\begin{tabular}{|l|r|r|r|r|r|r|r|r|r|}
\hline Singida & Mean & 0.09 & 0.12 & -0.03 & 26.0 & 21.2 & 23.0 & -3.8 & -3.0 \\
\hline$(354)(365)$ & Std. Dev. & 0.288 & 0.33 & & 0.438 & 0.410 & 0.421 & & \\
\hline Tabora & Mean & 0.02 & 0.14 & -0.12 & 11.0 & 4.2 & 10.4 & -6.8 & -0.6 \\
\hline$(376)(365)$ & Std. Dev. & 0.135 & 0.349 & & 0.317 & 0.201 & 0.305 & & \\
\hline Tanga & Mean & 0.15 & 0.18 & -0.03 & 29.0 & 30.4 & 32.6 & 1.4 & 3.6 \\
\hline$(335)(551)$ & Std. Dev. & 0.357 & 0.387 & & 0.453 & 0.460 & 0.469 & & \\
\hline TOTAL & Mean & 14.0 & 0.18 & -0.04 & 28.0 & 32.0 & 35.1 & 4.0 & 7.1 \\
\hline$(9377)$ & Std. Dev. & 0.351 & 0.384 & & 0.448 & 0.467 & 0.477 & & \\
\hline & & & 110435 & & & & & & \\
\hline & & & & & & & & & \\
\hline
\end{tabular}

Source: Authors calculation from DHS 2009-10 and UWEZO Tanzania 2010

Table 4: TANZANIA: HOUSEHOLD HAS DIRECT ACCESS TO PIPED WATER:

COMPARISON UWEZO TZ 2011 WITH DHS 2009-10 IN URBAN AND RURAL AREAS

\begin{tabular}{|c|c|c|c|c|c|c|c|}
\hline \multirow{2}{*}{\multicolumn{2}{|c|}{$\begin{array}{c}\text { Overall Difference DHS- } \\
\text { TZ_UWEZO > } 0.3\end{array}$}} & \multicolumn{3}{|c|}{ Urban } & \multicolumn{3}{|c|}{ Rural } \\
\hline & & \multirow{2}{*}{$\begin{array}{c}\text { DHS } \\
0.895\end{array}$} & \multirow{2}{*}{$\begin{array}{r}\text { Uwezo } \\
0.570\end{array}$} & \multirow{2}{*}{$\begin{array}{r}\text { DHS-Uwezo } \\
0.325\end{array}$} & \multirow{2}{*}{$\begin{array}{l}\text { DHS } \\
0.624\end{array}$} & \multirow{2}{*}{$\begin{array}{r}\text { Uwezo } \\
0.370\end{array}$} & \multirow{2}{*}{$\begin{array}{r}\text { DHS-Uwezo } \\
0.254\end{array}$} \\
\hline Arusha & Mean & & & & & & \\
\hline$(0.309$ & Std. Dev. & 0.308 & 0.495 & $* * *$ & 0.485 & 0.482 & $* * *$ \\
\hline $\mathrm{N}$ & & 126 & 1280 & & 285 & 3088 & \\
\hline Dar-es- & Mean & 0.513 & 0.310 & 0.203 & 0.054 & 0.580 & -0.526 \\
\hline$(0.349)$ & Std. Dev. & 0.500 & 0.464 & & 0.229 & 0.497 & $* * *$ \\
\hline $\mathrm{N}$ & & 673 & 8111 & & 57 & 109 & \\
\hline Pwani & Mean & 0.739 & 0.420 & 0.319 & 0.417 & 0.160 & 0.257 \\
\hline$(0.332)$ & Std. Dev. & 0.442 & 0.494 & **** & 0.494 & 0.364 & $* * *$ \\
\hline $\mathrm{N}$ & & 83 & 380 & & 187 & 2863 & \\
\hline \multicolumn{8}{|c|}{ Difference DHS-TZ UWEZO () between 0.2 and 0.3} \\
\hline Kilimanjaro & Mean & 0.708 & 0.690 & 0.153 & 0.618 & 0.390 & 0.228 \\
\hline$(0.216)$ & Std. Dev. & 0.457 & 0.465 & *** & 0.486 & 0.488 & *** \\
\hline $\mathrm{N}$ & & 198 & 812 & & 352 & 3973 & \\
\hline Manyara & Mean & 0.729 & 0.420 & 0.309 & 0.361 & 0.330 & 0.031 \\
\hline$(0.299)$ & Std. Dev. & 0.453 & 0.495 & $N S$ & 0.481 & 0.469 & $N S$ \\
\hline$N$ & & 26 & 855 & & 207 & 2495 & \\
\hline
\end{tabular}

Source: Authors calculation from DHS 2010 and UWEZO Tanzania 2011 
Table 5: UGANDA: COMPARING DHS (06/11-12/11) AND UWEZO (2011) ESTIMATES OF ACCESS TO WATER AND ELECTRICITY

\begin{tabular}{|c|c|c|c|c|c|c|c|}
\hline & \multicolumn{2}{|l|}{ DHS } & \multicolumn{2}{|r|}{ UWEZO } & \multicolumn{2}{|c|}{ Difference DHS-UWEZO } & \\
\hline & $\begin{array}{l}\text { Has } \\
\text { Electricity }\end{array}$ & $\begin{array}{l}\text { Access } \\
\text { to } \\
\text { Clean } \\
\text { Water }\end{array}$ & $\begin{array}{l}\text { Has } \\
\text { Electricity }\end{array}$ & $\begin{array}{l}\text { Access } \\
\text { to } \\
\text { Clean } \\
\text { Water }\end{array}$ & Has Electricity & $\begin{array}{l}\text { Access to } \\
\text { Clean Water }\end{array}$ & $\begin{array}{l}\text { Elec Std } \\
\text { Dev }\end{array}$ \\
\hline Central 1 & 26 & 35 & .24 & .27 & 2.32 & 8.0 & \\
\hline $\mathrm{N}$ & 1140 & 1140 & 9200 & 9200 & & & 0.000553 \\
\hline Std Dev & 0.44 & .462 & .425 & .444 & $* * *$ & $* * *$ & \\
\hline Central 2 & 17 & 27.9 & .10 & .17 & 6.54 & 12.2 & \\
\hline $\mathrm{N}$ & 1038 & 1038 & 12314 & 12314 & 0.000432 & 0.000431 & 2.08 \\
\hline Std Dev & 0.379 & .373 & .306 & .373 & $* * *$ & & \\
\hline Kampala & 77 & 79.0 & .79 & .68 & -0.60 & 10.6 & \\
\hline $\mathrm{N}$ & 797 & 797 & 4068 & 4068 & 0.000492 & 0.000501 & 2.22 \\
\hline Std Dev & 0.415 & .411 & .410 & .465 & & $* * *$ & \\
\hline East Central & 8 & 45.6 & .10 & .12 & -2.14 & 33.9 & \\
\hline $\mathrm{N}$ & 904 & 904 & 12188 & 12188 & 0.00032 & 0.000442 & 1.79 \\
\hline Std Dev & 0.27 & .379 & .302 & .321 & $* *$ & $* * *$ & \\
\hline Eastern & 6 & 39.2 & .05 & .07 & 0.51 & 32.1 & \\
\hline $\mathrm{N}$ & 1226 & 1226 & 17330 & 17330 & 0.000263 & 0.000416 & 1.62 \\
\hline Std Dev & 0.233 & .374 & .228 & .257 & & $* * *$ & \\
\hline West Nile & 3 & 34.8 & .04 & .05 & -1.19 & 29.712 .89 & \\
\hline $\mathrm{N}$ & 508 & 508 & 6930 & 6930 & 0.000226 & 0.000449 & 1.50 \\
\hline Std Dev & 0.181 & .383 & .200 & .220 & $*$ & $* * *$ & \\
\hline North & 5 & 22.9 & .06 & .13 & -0.65 & 10.2 & \\
\hline $\mathrm{N}$ & 757 & 757 & 9263 & 9263 & 0.000281 & 0.00037 & 1.68 \\
\hline Std Dev & 0.214 & .279 & .231 & .333 & & $* * *$ & \\
\hline Karamoja & 1 & 24.3 & .03 & .07 & -1.74 & 17.1 & \\
\hline $\mathrm{N}$ & 306 & 306 & 2879 & 2879 & 0.000187 & 0.000376 & 1.37 \\
\hline Std Dev & 0.097 & .212 & .163 & .262 & $*$ & $* *$ & \\
\hline Western & 9 & 18 & .06 & .10 & 3.44 & 8.24 & \\
\hline $\mathrm{N}$ & 1228 & 1228 & 16213 & 16213 & 0.000327 & 0.000438 & 1.81 \\
\hline Std Dev & 0.287 & .385 & .229 & .297 & $* * *$ & $* * *$ & \\
\hline Southwest & 12 & 23 & .08 & .11 & 4.48 & 11.64 & \\
\hline
\end{tabular}




\begin{tabular}{|c|c|c|c|c|c|c|c|}
\hline $\mathrm{N}$ & 1128 & 1128 & 10334 & 10334 & 0.000377 & 0.000489 & 1.94 \\
\hline Std Dev & 0.324 & .422 & .264 & .317 & $* * *$ & *** & \\
\hline Total & 18 & 25 & .11 & .14 & 6.7 & 10.6 & \\
\hline $\mathrm{N}$ & 9033 & 9033 & 100715 & 100715 & 4.55E-05 & $5.11 \mathrm{E}-05$ & 0.67 \\
\hline Std Dev & 0.383 & .431 & & & $* * *$ & $* * *$ & \\
\hline
\end{tabular}

Source: Authors calculation from DHS 2011 and UWEZO Uganda 2011 
Table 6 National Rates of Basic Water and Lighting Indicators from UWEZO surveys

\begin{tabular}{|c|c|c|c|c|c|c|}
\hline & \multicolumn{2}{|l|}{ Kenya } & \multicolumn{2}{|l|}{ Tanzania } & \multicolumn{2}{|c|}{ Uganda } \\
\hline & Water & Lighting & Water & Lighting & Water & Lighting \\
\hline 2011 & 24.7 & 17.0 & 28.0 & 18.0 & 14.0 & 11.0 \\
\hline 2012 & 25.6 & 15.0 & $29.0(31)$ & $18.0(17)$ & 13.0 & 12.0 \\
\hline
\end{tabular}

Table 7 Extrapolations for the three cities

\begin{tabular}{|c|c|c|c|c|c|c|c|}
\hline & $\begin{array}{l}2009 \\
\text { Census }\end{array}$ & $\begin{array}{l}\text { Access to } \\
\text { Water }\end{array}$ & Piped & $\begin{array}{l}\text { Census \& UWI } \\
\text { implications fo }\end{array}$ & $\begin{array}{l}\text { EZO correct, } \\
\text { r DHS }\end{array}$ & $\begin{array}{l}\text { DHS repres } \\
\text { Census, bu }\end{array}$ & $\begin{array}{l}\text { entative sample of } \\
\text { UWEZO of population }\end{array}$ \\
\hline & & $\begin{array}{l}\text { DHS } \\
\text { Estimate }\end{array}$ & $\begin{array}{l}\text { UWEZO } \\
\text { estimate }\end{array}$ & $\begin{array}{l}\text { DHS estimate } \\
\text { population }\end{array}$ & $\begin{array}{l}\% \text { missing } \\
\text { from DHS }\end{array}$ & $\begin{array}{l}\text { Correct } \\
\text { Population }\end{array}$ & $\begin{array}{l}\% \text { true population } \\
\text { missing in Census }\end{array}$ \\
\hline Nairobi & $3,138,000$ & 86.5 & 70.2 & $2,546,700$ & 18.9 & $3,866.6$ & $18.8 \%$ \\
\hline Dar Es salaam & $4,364,000$ & 66.9 & 32.0 & $2,087,400$ & 52.2 & $8,537,000$ & $51.1 \%$ \\
\hline Kampala & $1,516,210$ & 79 & 68 & $1,304,900$ & 13.9 & $1,716,479$ & $16.7 \%$ \\
\hline
\end{tabular}

